\section{A SEDUÇÃO DO LUGAR A HISTÓRIA E O FUTURO DAS CIDADES}

Joseph Rykwert

São Paulo: Martins Fontes, 2004.

\section{Paola Berenstein Jacques (UFBa)}

O último livro de Joseph Rykwert, recentemente traduzido e lançado no Brasil com a presença do autor em São Paulo e Salvador, volta a tratar das questôes urbanas, mas ao contrário do seu primeiro livro - The idea of the town: the Anthropology of urban form in Rome, Italy, and the Ancient World - que se interessava mais pelo passado das cidades, para a idéia de cidade na antiguidade, o livro atual tem um claro interesse pela cidade contemporânea, e como o subtítulo da tradução indica, pelo futuro das cidades.

Em todo trabalho de Rykwert, historiador extremamente singular, o passado é revisitado com um olhar sobre o presente, e, particularmente, como uma crítica construtiva ao movimento moderno em arquitetura e urbanismo. Ao escrever sobre temas bem heterodoxos - que vão da Casa do Adão no Paraíso aos Primeiros modernos, os arquitetos do século XVIII, passando pela Coluna dançante - Rykwert demonstra uma preocupação constante com o destino da arquitetura moderna, seja ao tratar das cabanas primitivas, das colunas dóricas, dos ornamentos em geral, ou ainda, das cidades romanas.

Joseph Rykwert emigra da Polônia para a Inglaterra em 1939, fugindo da crescente perseguição aos judeus na Europa continental. A sua formação em arquitetura e urbanismo se deu em Londres (Bartlett School e Architectural Association School), cidade onde vive até hoje. É importante lembrar que Londres e Amsterdã foram as sedes principais do Team $\mathrm{X}^{1}-$ grupo de jovens arquitetos modernos que iniciaram a crítica aos preceitos dos CIAMs (Congressos Internacionais

1 Team X, por ser o grupo responsável pela organização do CIAM X, de 1956.

2 A Carta de Atenas se refere às discussões acerca da Cidade Funcional travadas durante o CIAM IV a bordo do Patris II na travessia MarseIha-Atenas em 1933. A Carta só foi publicada dez anos depois, durante a ocupação alemã de Paris, pelo próprio Le Corbusier. Outra versão dos debates foi publicada por J.-L. Sert, exilado nos Estados Unidos, no seu livro Can our cities survive?

3 Peter Smithson costumava dizer que na Carta de Atenas "what was missing was man" ["o que estava faltando era o homem"]. de Arquitetura Moderna), principalmente em relação ao urbanismo, ao contestar a famosa Carta de Atenas ${ }^{2}$ redigida por Le Corbusier. Rykwert sempre esteve bem próximo de integrantes deste grupo e, em particular, de seus amigos Peter Smithson ${ }^{3}$ e Aldo Van Eyck. ${ }^{4}$

O Team X propôs, ainda nos anos 50, recolocar nos projetos o homem real das ruas no lugar do Modulor, homem ideal, de Le Corbusier e da "velha guarda" dos CIAMs. As questóes das diferenças individuais passaram a ser estudadas no lugar do coletivo ideal. A idéia principal era a de devolver a cidade a seus habitantes. O grupo era heterogêneo e eclético mas tinha a convicção comum de ir contra a doutrina da Carta de Atenas. Joseph Rykwert continua até hoje seguindo esta linhagem teórica, ao insistentemente buscar alternativas ao modernismo ${ }^{5}$ ao longo de toda sua obra. Pode-se notar uma influência direta de Van Eyck, sobretudo temática, ligada ao estudo da mitologia e dos rituais, ou seja, ao resgate de um simbolismo primitivo claramente ausente do racionalismo do pensamento moderno.

O autor, mesmo ao trabalhar com temas bastante díspares, demonstra sempre uma preocupação humanista com a organização do espaço em geral, seja na escala arquitetônica ou urbana. Seu interesse central está no estudo das formas pelas quais o homem organiza seu espaço, seja este uma cabana primitiva ou a cidade contemporânea. Ao longo de seus textos são estudados os conteúdos simbólicos das sociedades e das cidades, as diferenças culturais, religiosas, psicológicas, e, principalmente, a simbologia das formas resultantes. Em oposição clara à Carta de Atenas, que pretendia eliminar as diferenças e conflitos da cidade moderna, Rykwert

4 Aldo Van Eyck, um dos primeiros arquitetos a contestar o racionalismo dos CIAMs, já dizia em 1947 que "CIAM knows that the tiranny of cartesian common sense has reached its final stage" ["O CIAM sabe que a tirania do senso comum cartesiano alcançou seu ápice"]. Van Eyck também foi um dos precursores do estudo da arquitetura vernácula, em particular dos Dogons, cf.: Meaning in Architecture, Londres: Barrie/Rockliff, 1969 (livro paradigmático das ideias pós-Maio de 1968, conseqüência do pensamento do Team X, dos situacionistas e dos seguidores da semiologia, com textos, além dos de Van Eyck, do próprio Rykwert, e de, entre outros: Reyner Banham, George Baird, Nathan Silver, Kenneth Frampton e Françoise Choay).

5 Uso o termo modernismo de forma pejorativa para indicar a massificação como uma perda de qualidade da arquitetura moderna construída em larga escala, para o menor número de pessoas e da forma mais rápida possível (pré-fabricada). 0 urbanismo proposto por Le Corbusier, exposto como uma doutrina na Carta de Atenas, foi massificadamente construído na Europa do pós-guerra, principalmente sob a forma de enormes conjuntos habitacionais modernistas (muitas vezes repetições dos mesmos projetos em série). 
quer mostrar que são exatamente essas diferenças e conflitos que tornam as cidades lugares mais sedutores.

Em $A$ sedução do lugar, com um texto mais voltado para o "grande público" do que o habitual, Rykwert faz um apelo a favor da participação e da ação comunitária, das iniciativas de cidadãos em protestos coletivos para resolução de problemas urbanos. Trata da responsabilidade de arquitetos e urbanistas (mea culpa corporativo) e lembra que toda a ação urbanística é antes de tudo política. Além de propor um maior envolvimento público dos habitantes, o autor também ressalta diferentes maneiras de se resolver questôes urbanas, ou seja, de se passar do protesto ao projeto. Com um discurso muito próximo ao de Jane Jacobs em Morte e vida das cidades americanas, Rykwert comenta sobre o "mal-estar urbano" e os possíveis "remédios" para melhorá-lo. ${ }^{6}$ Defende a sutileza e a modéstia nas intervenções urbanas, ${ }^{7}$ e termina o livro invertendo uma máxima de Daniel Burnham ${ }^{8}$ que dizia: "Não faça planos pequenos". Joseph Rykwert, por sua vez, aconselha: "Faça planos pequenos, e muitos deles".

No epílogo da edição brasileira, escrito quatro anos após o original em inglês, o autor, como não poderia deixar de ser, cita o caso do onze de setembro em Nova York, e comenta o ataque terrorista às torres gêmeas mostrando como este reforça, de uma forma particularmente dramática, a questão do valor simbólico $\mathrm{da}$ arquitetura. Para quem não conhece esta ironia da história da arquitetura, as torres gêmeas do World Trade Center, destruídas em 2001 no ataque terrorista (e que já tinham sido alvo de um atentado em 1993), foram inauguradas em 1972, quando ainda eram as torres mais altas do mundo, o que simbolizava o poderio econômico dos EUA e reforçava a posição central de Nova York no comércio mundial, como o nome do prédio indica. E 1972 foi também o ano conhecido como o início nos EUA do chamado "pós-modernismo" em arquitetura, principalmente por causa da implosão controlada do Pruitt Igoe, um conjunto habitacional

6 Na época da publicação do livro de Jacobs (1961), Lewis Mumford publica na New Yorker um artigo crítico com o irônico título: "Mamãe Jacobs e seus remédios para o câncer urbano". Jane Jacobs rebateu afirmando que além, de machista, Mumford nunca gostou de grandes cidades como Nova York.

7 Os projetos e intervenções urbanas são cada vez mais espetaculares e midiáticas nas mais recentes revitalizações urbanas, que sempre acabam por expulsar a população mais pobre do local (gentrification). 8 Autor do Plano de Chicago de 1909, um modelo para a modernização das cidades nos EUA. modernista, o que para Charles Jencks simbolizou o enterro oficial do movimento moderno. ${ }^{9} \mathrm{O}$ conjunto Pruitt Igoe foi projetado pelo mesmo arquiteto, Minoru Yamasaki, do World Trade Center. Yamasaki passou a ser um dos arquitetos mais conhecidos do mundo por suas obras implodidas, talvez por ser também um dos que mais tenha tornado explícita e inequívoca esta função simbólica em sua arquitetura, ao criar ícones midiáticos e espetaculares, que acabaram se tornando alvos.

Rykwert chama atenção para esta função simbólica, ou melhor, metafórica, da arquitetura. Ou ainda, alerta para seu poder metafórico, que foi tragicamente reafirmado pelos terroristas em setembro de 2001. Protesta contra a arrogância da arquitetura, contra a megalomania dos projetos faraônicos contemporâneos, e propõe, no lugar dos megamonumentos, projetos mais modestos, mais sutis, em suma, mais humanos. $\mathrm{O}$ epílogo ganha um tom mais panfletário do que o resto do livro, como se o ataque terrorista tivesse explicitado, de forma trágica, o que o autor já tinha tentado dizer de forma indireta, e que poderia ser resumido na seguinte equação: pressão cívica $\mathrm{x}$ função simbólica.

Joseph Rykwert deixa uma mensagem final bem clara. Ele pede para que os arquitetos e urbanistas prestem mais atenção às possíveis conseqüências do que eles projetam; e para que os cidadãos em geral prestem mais atenção aos projetos dos arquitetos e urbanistas, e também às posições quanto às questōes urbanas dos políticos responsáveis. Quase um slogan do tipo: ao votar pense na forma de cidade que você deseja! O recado fica ainda mais explícito no final do texto: "Não liguem para as opiniões de seus candidatos sobre aborto e direitos dos homossexuais - ou qualquer outro interesse de facçôes, por mais importantes que sejam. Interroguem-no sobre a sua posição sobre assuntos que dizem respeito à tessitura da cidade, perguntem-lhe se ele sabe que o tecido da cidade é uma metáfora da sociedade que você e ele querem viabilizar".

90 movimento moderno já tinha terminado com o final dos CIAMs e a construção em massa de conjuntos habitacionais já vinha sendo muito criticada na Europa desde os anos 50, principalmente pelo próprio Team $\mathrm{X}$ e pelos situacionistas. 